\title{
ARBORIZAÇÃO URBANA NA CIDADE DE SÃO JOSÉ DO CERRITO, SC: DIAGNÓSTICO E PROPOSTA PARA ÁREAS DE MAIOR TRÂNSITO
}

\author{
Renato Pinheiro ${ }^{1,4}$, Eduardo Franchin ${ }^{1}$, Roberta Sabatino Ribeiro ${ }^{2}$, Wagner Wolff ${ }^{1}$, Ana \\ Carolina da Silva ${ }^{3}$, Pedro Higuchi ${ }^{3}$
}

(recebido em 12.11.2009 e aceito para publicação em 29.12.2009)

\begin{abstract}
RESUMO
As árvores que compõem a arborização urbana exercem importantes funções ecológicas e melhoram a harmonia estética das cidades. Este trabalho teve como objetivos diagnosticar a arborização urbana das áreas de maior trânsito na cidade de São José do Cerrito, SC, detectar possíveis problemas na arborização atual, identificar locais não arborizados e propor soluções para melhorar a arborização existente. Para isso, foram avaliadas as ruas da cidade com maior fluxo de pedestres e de veículos e as praças centrais, onde as árvores foram identificadas, mensuradas e avaliadas quanto a sua ocupação no espaço, presença de injúrias e condições fitossanitárias. Foi encontrada baixa riqueza de espécies, com a predominância de Ligustrum japonicum Thunb., espécie exótica plantada e conduzida de forma inadequada, devida a interferência nas calçadas e na fiação elétrica. A sugestão é que se faça a retirada de grande parte das árvores existentes, mantendo somente as nativas e algumas exóticas com valor histórico. A substituição deve ser feita por espécies nativas adaptadas à região que, além de fornecer melhorias estéticas à cidade, irão auxiliar na manutenção da biodiversidade florística da Floresta Ombrófila Mista e na atração da fauna local, fornecendo alimento e habitat.
\end{abstract}

Palavras-chave: Arborização urbana, Ligustrum japonicum, Planalto Catarinense.

1. Graduandos do curso de Engenharia Florestal da Universidade do Estado de Santa Catarina. Lages/SC.

2. Graduanda do curso de Agronomia da Universidade do Estado de Santa Catarina. Lages/SC.

3. Professores do Departamento de Engenharia Florestal, Universidade do Estado de Santa Catarina, Av. Luiz de Camões, 2090, Bairro Conta Dinheiro, Lages, SC, CEP: 88520-000.

4. E-mail para contato: alceurpinheiro@yahoo.com.br 


\title{
URBAN FORESTRY IN THE CITY OF SÃO JOSÉ DO CERRITO, SC: DIAGNOSIS AND PROPOSALS FOR AREAS OF HIGHER TRAFFIC
}

\begin{abstract}
Urban trees provide many benefits for the city environment, offering important ecological functions and enhancing the aesthetic harmony. The aims of this study were to investigate the urban forestry of high traffic areas in the city of São José do Cerrito, SC, detecting possible problems in the current urban trees, identify places without trees and suggest solutions to improve the urban forest. For this sake, the urban trees of streets with higher traffic and central squares were evaluated through tree botanical identification, measurement and evaluation regards its spatial occupancy, injury presence and phytosanitary conditions. The results demonstrated that the urban forest is characterized by a low tree richness with the dominance of mismanaged Ligustrum japonicum Thunb., an exotic tree, planted in wrong places, due to the damage in side-walks and affections in power lines. The replacement of the most current trees, keeping just the native species and the historically important trees, by native species adapted to the region climate is required to improve the urban forest. This procedure will enhance the city landscape beauty and could contribute to the maintenance of the Araucaria forest biodiversity.
\end{abstract}

Key-words: urban forestry, Ligustrum japonicum, Planalto Catarinense.

\section{INTRODUÇÃO}

Entende-se por arborização urbana toda cobertura vegetal de porte arbóreo existente nas cidades, que ocupa basicamente três espaços distintos: as áreas livres de uso público e potencialmente coletiva, as áreas livres particulares e as áreas que acompanham o sistema viário (Rodrigues et al., 2002).

Nas cidades, as árvores exercem importantes serviços ecológicos, como purificação do ar, pela retenção de partículas de poeira e fixação do carbono atmosférico, melhoria do microclima, por meio da evapotranspiração e geração de sombra, redução da velocidade do vento, amortecimento de ruídos, influência positiva no balanço hídrico, favorecendo a infiltração da água no solo, fornecimento de abrigo e alimento para a fauna, propiciando uma maior biodiversidade, e, em conseqüência, maior equilíbrio das cadeias alimentares e diminuição de pragas e agentes vetores de doenças, e a formação de corredores ecológicos (Rodrigues et al., 2002). Uma cidade bem arborizada também possui a estética mais 
harmoniosa, principalmente quando há alta diversidade de espécies arbóreas, valorizando o município, trazendo benefícios aos moradores e atraindo visitantes.

Porém, podem ocorrer problemas quando árvores inadequadas para o espaço no qual foi plantada competem com outros elementos urbanos, como fiações elétricas, encanamentos, calhas, calçamentos, muros, postes de iluminação, etc. (Rodrigues et al., 2002). A escolha adequada de uma espécie arbórea para ocupar um determinado espaço é um dos aspectos mais importante a ser considerado, devendo ser observados a presença de fiação aérea e de outros elementos urbanos, a largura da calçada e o recuo das edificações (Rodrigues et al., 2002).

São José do Cerrito é um município pouco populoso, com aproximadamente 10.000 habitantes, onde $70 \%$ destes vivem na área rural. Dentre os municípios vizinhos, destaca-se Lages que, juntamente com outros municípios do entorno, são conhecidos como importantes pólos do turismo rural no Brasil. A área urbana de São José do Cerrito apresenta poucas árvores e ainda possui muitas ruas sem pavimentação e calçadas. Essa situação reforça a necessidade de um projeto técnico de urbanização, juntamente com o de arborização, para que o município possa usufruir os benefícios já destacados da arborização urbana, o que melhoraria a qualidade de vida. Além disso, com o plantio bem conduzido de espécies adequadas, seria possível melhorar a estética da área urbana do município, o que seria um atrativo para turistas, aumentando, assim, a fonte de renda no município.

Neste sentido, este trabalho foi realizado com os objetivos de: i) identificar, mensurar e avaliar as árvores das áreas de maior trânsito na cidade de São José do Cerrito, SC; ii) verificar a adequação das mesmas ao local estudado, detectando possíveis problemas na arborização, como interferência da copa e do sistema radicular nos elementos urbanos e no trânsito de veículos e pedestres, presença de injúrias, problemas fitossanitários, inclinação do fuste e podas mal executadas; iii) identificar trechos não arborizados e verificar a possibilidade de arborização nestes locais; e iv) propor soluções para melhorar a arborização urbana existente e propor espécies adequadas nos locais não arborizados.

\section{MATERIAIS E MÉTODOS}

\section{Descrição da área de estudo}

São José do Cerrito (lat $=27^{\circ} 39^{\prime} 47^{\prime \prime} S$; long $=50^{\circ} 34^{\prime} 48^{\prime \prime} \mathrm{W}$ e alt $=910 \mathrm{~m}$ ) é um município de 10.394 habitantes e de área de $969 \mathrm{~km}^{2}$ localizado no Planalto Serrano de Santa Catarina que tem a agricultura e a pecuária como a base econômica (IBGE, 2008). O clima é caracterizado como mesotérmico úmido, com temperaturas médias de $21,5^{\circ} \mathrm{C}$ e 
chuvas bem distribuídas durante o ano (Cerrito, 2008). A precipitação média anual varia entre 1.300 e 1.500 mm na região (Instituto Cepa/SC, 2009). A Bacia Hidrográfica que está inserida o município é a do Rio Canoas e do Rio Pelotas, com topografia, em sua maior parte, suave-ondulada a forte ondulada. Os solos são ácidos, com teor de alumínio trocável de médio a alto e baixo teor de matéria orgânica, sendo a maioria classificados, segundo o Instituto Cepa/SC (2009), como Cambissolos, Argissolos, Neossolos e Latossolos.

A vegetação nativa é formada por floresta de Araucária e campos de altitude que, segundo a classificação do IBGE (1992), pode ser classificada como Floresta Ombrófila Mista Montana e Alto-Montana.

\section{Diagnóstico da arborização atual}

Para diagnóstico da atual arborização das áreas de maior trânsito da cidade, nos meses de agosto a outubro de 2008, foram mensuradas, identificadas e avaliadas as árvores das cinco ruas com maior tráfego de pedestres e veículos: Rua Anacleto da Silva Ortiz, rua principal da cidade que possui um trecho de $230 \mathrm{~m}$ que passa, atualmente, por um processo de reurbanização (o trecho possuiu a maior concentração do comércio da cidade); Rua Herculano Pereira dos Anjos, transversal à rua principal da cidade; Rua Manoel Batista de Oliveira; Rua João Otávio Garcia; e Rua Edite Batista (Figura 1). Além disso, estas ruas estão entre as poucas que possuem arborização viária.

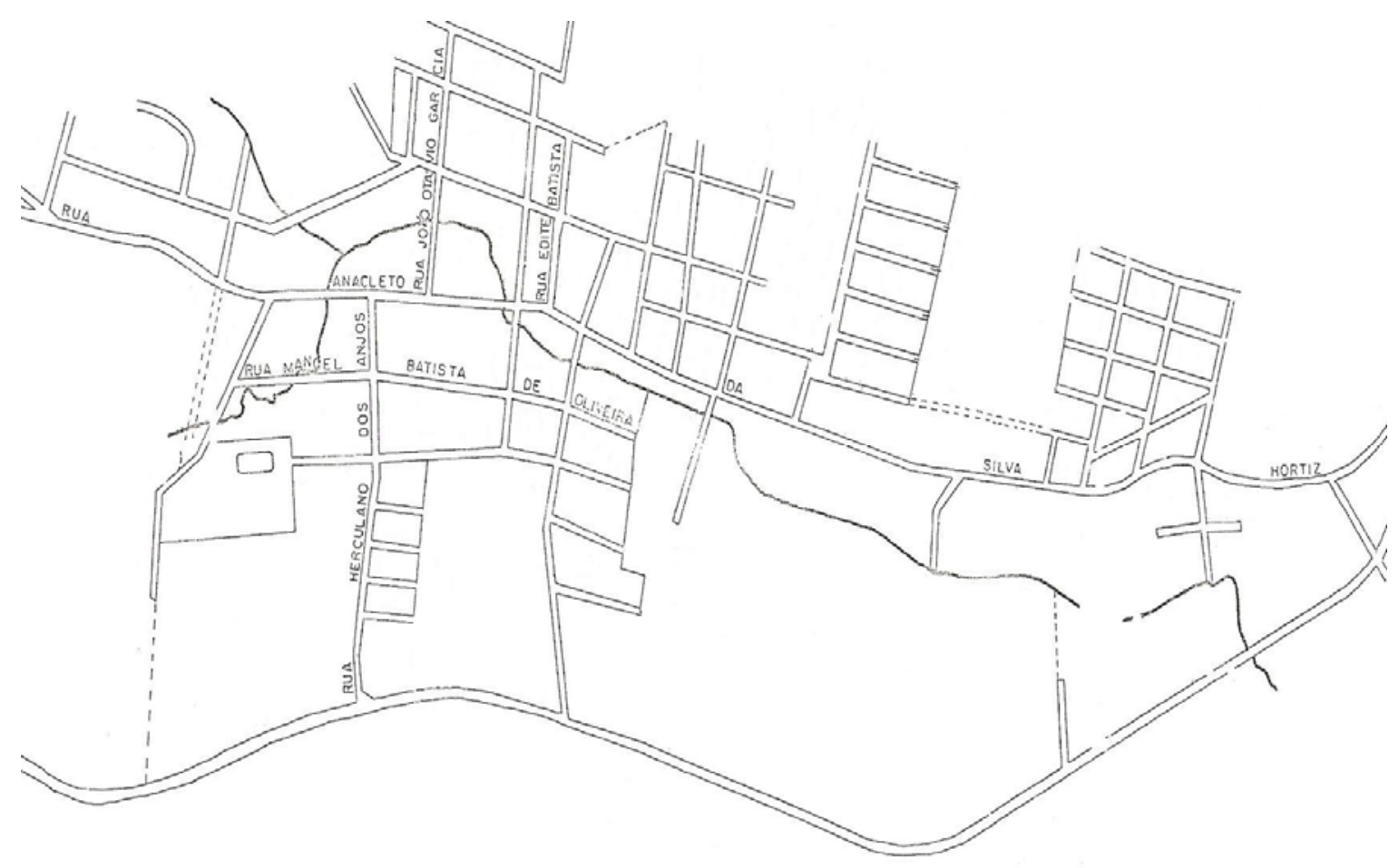


Figura 1. Ruas avaliadas para o diagnóstico da arborização urbana nas áreas de maior trânsito na cidade de São José do Cerrito, SC.

Também foram avaliadas as árvores das três praças que a cidade possui, todas localizadas na região central: Praça Clóris Judith da Silva, adjacente a Rua Anacleto da Silva Ortiz que, que é um ponto de encontro de crianças e idosos, possuindo "playground" e "academia da terceira idade", Praça da Igreja Matriz São Pedro e Praça da Prefeitura Municipal.

Com o auxílio de trena e fita métrica foram feitas medições das árvores e do espaço ocupado por elas. As características analisadas de cada árvore foram: i) localização e identificação (espécie; tipo de imóvel em frente à árvore e largura da calçada); ii) dimensões da árvore (altura total, altura da primeira ramificação, diâmetro médio da projeção da copa DPC e circunferência a altura do peito - CAP); biologia (injúrias, fitossanidade pela análise visual, sistema radicular, inclinação do fuste, presença e características de flores, frutos e folhas); entorno e interferências (distância do eixo da árvore até o meio fio, distância do eixo da árvore até as edificações, distância da árvore até a árvore mais próxima, interferência da copa, tipo de pavimento, tráfego de pessoas, interferência na fiação acima da árvore e em placas de sinalização); e ações (ação executada, como podas, por exemplo, qualidade da ação e ação recomendada).

As identificações foram feitas por meio de consultas a especialistas e literatura especializada, as espécies foram classificadas em famílias de acordo com o sistema APG II (Angiosperm Phylogeny Group II, 2003) e as grafias dos nomes dos autores foram uniformizadas, seguindo a padronização proposta por Brummitt \& Powell (1992).

\section{Proposta de arborização}

A proposta de arborização foi feita com base no diagnóstico realizado em relação à localização das deficiências da atual arborização.

\section{RESULTADOS E DISCUSSÃO}

\section{Diagnóstico da arborização atual}

\section{Ruas}

A Rua Anacleto da Silva Ortiz possui $2 \mathrm{~km}$ de comprimento por $11 \mathrm{~m}$ de largura. A rua foi analisada em duas partes: i) o trecho de $230 \mathrm{~m}$ da rua que será reurbanizado e 
pavimentado, no qual todas as árvores foram mensuradas, identificadas e avaliadas, e ii) o restante da rua, o qual foi feito um caminhamento para identificação e avaliação qualitativa das espécies.

i) Onze árvores situavam-se no trecho a ser pavimentado (cerca de $230 \mathrm{~m}$ ), sendo estas pertencentes apenas a duas espécies exóticas: Ligustrum japonicum Thunb. (alfeneiro, família Oleaceae) e Quercus robur Thunb. (carvalho, família Fagaceae), com 10 e um indivíduos, respectivamente.

O carvalho encontrava-se isolado de outras árvores (distância da árvore mais próxima de $45 \mathrm{~m}$ ), em um canteiro em frente a uma construção (distância do eixo da árvore até o muro de $2 \mathrm{~m}$ ) e sem interferência no trânsito de pedestres ou de veículos (altura da primeira ramificação de $2 \mathrm{~m}$ e do eixo da árvore até o meio fio de 3,3 $\mathrm{m}$ ). A altura era de aproximadamente $20 \mathrm{~m}$, o diâmetro de projeção da copa médio (DPC) de $18 \mathrm{~m}$ e a circunferência a altura do peito (CAP) de 3,4 m. A copa da árvore estava interferindo na fiação e em um poste, porém, considerando a importância histórica da árvore, é sugerido que haja uma reformulação nestes elementos urbanos, de forma a conservar a árvore como patrimônio histórico. A árvore não apresentava problemas fitossanitários e injúrias e não foi observado afloramento radicular e inclinação de fuste. No período de observação (mês de agosto de 2008), este indivíduo apresentou-se com muitas folhas e início de florescimento. A pavimentação que se encontrava o carvalho é de pedras, com o canteiro de pequenas dimensões, por isso, é sugerido, para conservação deste indivíduo e melhor aproveitamento do espaço, que seja feita a reformulação da área em volta da árvore, com o redimensionamento do canteiro, aumentando o espaço de infiltração de água no solo, e a construção de bancos, formando uma pequena praça, de forma que este indivíduo seja valorizado e tornando o local um ponto de encontro público.

Os alfeneiros (Ligustrum japonicum) presentes na rua estavam em calçadas com largura média de 2,2 m, a maioria deles em frente de construções e abaixo da fiação elétrica. Alguns dias após a avaliação, devido ao novo projeto de reurbanização proposto pela prefeitura para a pavimentação da rua principal, todos os alfeneiros presentes no trecho da rua de $240 \mathrm{~m}$ foram retirados, restando apenas os presentes no restante da rua e em ruas secundárias. A ação da prefeitura de retirar estes indivíduos foi positiva, pois estes interferiam no trânsito de pedestres (altura média da primeira ramificação de 1,5 m). Além disso, Ligustrum japonicum é uma espécie considerada invasora por competir com espécies nativas em área naturais, ocorrendo de forma subespontânea em remanescentes de Floresta Ombrófila Mista e de Floresta Ombrófila Densa, especialmente áreas alteradas e com sombreamento menos denso (Instituto Horus, 2009). 
Os alfeneiros retirados estavam adequados ao espaço do passeio, pois a distância do eixo da árvore até o meio fio foi, em média, de 0,63 m (sendo que o recomendado é de no mínimo de $50 \mathrm{~cm}$ ), e a distância média do eixo da árvore até as edificações foi de 1,9 m. Porém, aproximadamente $29 \%$ dos alfeneiros apresentavam sistema radicular em afloramento e $36 \%$ estavam afetando as calçadas. Além disso, o espaçamento entre árvores mostrava-se muito desuniforme, com variação de 0,5 até $60 \mathrm{~m}$ de distância entre árvores, o que, além de interferir na fisiologia dos indivíduos, provocando crescimentos desuniformes, prejudica a estética da arborização. A maioria dos indivíduos apresentava estado geral regular, com lesões graves quando estas estavam presentes, verificando-se, também, fungos nos ramos e caules e presença de algumas pteridófitas. A maior parte dos indivíduos possuía poucas folhas, sem flores ou frutos, devido à realização de podas mutiladoras. Por isso, mesmo sendo indivíduos adultos e de médio porte (CAP médio de 79,3 cm), estes não interferiam na fiação elétrica (altura média das árvores de 3,4 m e DPC médio de 1,88 m).

ii) No restante da rua não realizou-se a reurbanização e não foram retiradas árvores. Neste trecho, foram encontrados 85 indivíduos (Tabela 1) sendo, em sua maioria, indivíduos jovens em boas condições. Das espécies encontradas, somente Schinus molle L. e Araucaria angustifolia (Bert.) Kuntze são espécies nativas. Estes indivíduos estavam plantados em um trecho da rua sem calçada e do lado oposto da fiação elétrica.

Tabela 1 - Espécies arbóreas encontradas no trecho não reurbanizado da Rua Anacleto da Silva Ortiz em São José do Cerrito, SC.

\begin{tabular}{|c|c|c|c|}
\hline Nome Científico & Família & Nome Popular & $\begin{array}{l}\text { Número de } \\
\text { indivíduos }\end{array}$ \\
\hline Ligustrum japonicum Thunb. & Oleaceae & Alfeneiro & 45 \\
\hline Schinus molle L. & Anacardiaceae & Aroeira-salsa & 14 \\
\hline Cupressus sp. & Cupressaceae & Cipreste & 8 \\
\hline Acer rubrum L. & Aceraceae & Ácer-rubro & 7 \\
\hline Araucaria angustifolia (Bert.) Kuntze & Araucariaceae & Araucária & 5 \\
\hline Melia azedarach L. & Meliaceae & Cinamomo & 4 \\
\hline Cryptomeria japonica D. Don. & Taxodiaceae & Pinheiro-do-Japão & 2 \\
\hline Total & & & 85 \\
\hline
\end{tabular}

A Rua Herculano Pereira dos Anjos, de 200 m de comprimento, possuía três indivíduos jovens de Ligustrum japonicum, em passeio sem calçamento. Estes indivíduos estavam localizados abaixo da fiação elétrica, porém, por serem jovens, ainda não estavam interferindo na fiação. 
Juntamente com a Rua Anacleto da Silva Ortiz, a Rua Manoel Batista de Oliveira foi considerada uma das ruas mais importantes da cidade, devido ao maior tráfego de veículos e pedestres. Por ser paralela a Rua Anacleto, mão única desde 2008, tem recebido o tráfego de veículos do sentido contrário da Rua Anacleto. Apesar de sua grande importância na cidade, suas vias de $620 \mathrm{~m}$ de comprimento não eram arborizadas, possuindo também o calçamento dos passeios deficiente, presente somente em alguns trechos.

Na Rua João Otávio Garcia, com 265 m de comprimento, foram observados somente 14 alfeneiros de espaçamento irregular entre eles, que não exerciam interferência na fiação elétrica, nem nas construções.

A Rua Edite Batista, de cerca de 200 m de comprimento, possuiu em sua composição arbórea 18 indivíduos de Ligustrum japonicum e cinco de Handroanthus albus (Cham.) Mattos (Ipê-amarelo, família Bignoniaceae). O ipê-amarelo destaca-se por ser uma espécie nativa da Floresta Ombrófila Mista. O espaçamento entre os indivíduos arbóreos era irregular e estes não interferiam na rede elétrica e em construções.

Poucas ruas centrais da cidade possuíam arborização, em geral, com poucas árvores, com espaçamentos irregulares entre si, e muitas vezes em ruas e passeios sem calçamento.

\section{Praças}

$\mathrm{Na}$ Praça Clóris Judith da Silva foram encontrados 10 indivíduos arbóreos, sendo um da espécie Pyrus communis L. (pereira, família Rosaceae), dois da espécie Araucaria angustifolia, três da espécie Syagrus romanzoffiana (Cham.) Glassman (jerivá, família Arecaceae) e quatro da espécie Ligustrum japonicum.

A pereira, uma espécie exótica, tinha altura aproximada de $10 \mathrm{~m}$, CAP de 1,69 m e DCP de 7,00 m. É importante a sua manutenção, pois o indivíduo oferece frutos para a fauna e para a população da cidade (na época do inventário esta não apresentava flores e frutos). Porém, ela apresentou-se com lesões causadas por podas mal conduzidas, que também causou efeito estético negativo, pois prejudicou a conformação original da árvore. Apesar disso, o estado geral do indivíduo era bom, sem ataque evidente de pragas e doenças e sem interferir no tráfego de pedestres (primeira ramificação a $2 \mathrm{~m}$ de altura). $\mathrm{A}$ árvore também não interferia nos elementos da cidade, como postes de iluminação, nem estava em competição com outros indivíduos da praça $(9 \mathrm{~m}$ de distância da árvore mais próxima).

As duas araucárias, de altura aproximada de 13 e 22 m, DPC de 9,00 e 13,00 m, e CAP de 1,20 e 2,07 m, respectivamente, estavam em bom estado, sem injúrias e ataque evidente de pragas e doenças. As árvores não interferiam no tráfego de pedestres (altura da 
primeira ramificação de 5,5 e 9,3 m, respectivamente) e nem em elementos da cidade. Porém, observou-se um muro próximo a uma das árvores (distanciado 0,39 m), mas que não estava sofrendo interferência evidente. Não houve presença de estróbilos nos indivíduos na época do inventário.

Os três indivíduos de Syagrus romanzoffiana, também uma espécie nativa importante para a fauna, apresentavam altura média de 4,3 m, DPC médio de 2,71 m e CAP médio de $46 \mathrm{~cm}$. Todas as plantas apresentavam estado geral bom, sem lesões ou ataques evidentes de pragas e doenças. Um dos indivíduos apresentou interferência na fiação acima da copa e, devido à não tolerância das espécies da família Arecaceae à poda, é sugerido que esse indivíduo seja transplantado para um local mais adequado da praça.

As Praças da Igreja Matriz São Pedro e da Prefeitura Municipal apresentavam a estética harmoniosa, porém, houve o mesmo padrão das outras áreas avaliadas em relação à valorização de espécies exóticas e a pouca utilização de espécies nativas. Como espécie nativa utilizada destacou-se o Syagrus romanzoffiana e, como espécies exóticas, a Cryptomeria japonica e a Thuja sp.

No Brasil, há predomínio da arborização de municípios com espécies exóticas, ocasionando problemas, como a invasão biológica, que é representada pela invasão de algumas dessas espécies em ambientes naturais adjacentes às cidades, ocupando o lugar de espécies nativas por serem, muitas vezes, competidoras mais agressivas e não possuírem inimigos naturais (Silva, 2008). A introdução de espécies exóticas é a segunda maior causa de perda de biodiversidade no mundo. Segundo Silva (2008), há excessiva utilização de indivíduos de Ligustrum spp. na Região Sul do Brasil, espécies que possuem a vantagem competitiva por possuírem rápido crescimento, colonizando facilmente áreas naturais, sendo, por isso, adicionadas à lista de espécies invasoras do Estado do Paraná.

A arborização urbana realizada nos municípios de Curitiba, Irati e Pato Branco, no Estado do Paraná, e Horizontina, no Estado do Rio Grande do Sul, são exemplos da arborização na Região Sul do Brasil, com excessiva utilização de espécies exóticas. Milano (1985), estudando a arborização urbana de Curitiba, encontrou quase 40\% dos indivíduos pertencentes às espécies exóticas Lagerstroemia indica (extremosa, família Lythraceae) e Ligustrum lucidum W. T. Aiton (alfeneiro, família Oleaceae). Em Irati, Coltro e Miranda (2007) concluíram que 55\% dos indivíduos arbóreos eram de três espécies exóticas amplamente utilizadas na arborização urbana da Região Sul: extremosa, alfeneiro, e acernegundo. Na região central de Pato Branco, Silva et al. (2007) encontraram 62,4\% dos indivíduos de Ligustrum lucidum. Ainda em Pato Branco, nos bairros Bancários, Brasília e Pinheiros, Silva et al. (2008) encontraram predominância de Ligustrum lucidum, com 39\% 
dos indivíduos, e Lagerstroemia indica, com 19\%. Já Floriano et al. (2004) encontraram, na região central de Horizontina, Ligustrum japonicum como a espécie mais abundante.

A semelhança entre vários municípios na arborização urbana, utilizando-se as mesmas espécies exóticas, inviabiliza que estes tenham uma identidade arbórea, prejudicando o turismo da região, pois o turista é atraído pelas peculiaridades paisagísticas (Silva, 2008). Segundo Silva (2008), as pessoas, quando viajam, desejam conhecer paisagens urbanas diferentes e, no entanto, acabam deparando sempre com as mesmas árvores, podendo trazer conseqüências negativas para a economia do município.

\section{Proposta de arborização}

\section{Ruas}

Devido aos problemas de arborização detectados nas áreas de maior trânsito na cidade de São José do Cerrito (e.g. baixa riqueza de espécies, grande dominância de indivíduos de Ligustrum japonicum, uso de espécies inadequadas, que interferem na fiação elétrica e na calçada, falta de arborização na maioria das ruas), são sugeridas algumas substituições e o plantio de espécies com o porte adequado ao local, incorporando também maior quantidade de espécies nativas e maior diversidade florística. Segundo Grey \& Deneke (1978), cada espécie deve entrar na composição florística proposta até o limite máximo de $15 \%$ da quantidade total. Esse aumento da diversidade florística é desejável para: i) melhorar os efeitos estéticos da arborização, aumentando, também, o período de florescimento (utilizar espécies que florescem em diferentes épocas), de forma e de cores diferentes de flores; ii) manutenção da biodiversidade, em função da atração de diferentes polinizadores e dispersores, devido ao maior fornecimento de alimentos e abrigo para a fauna; iii) sob o ponto de vista fitossanitário, o risco de perda parcial ou total da arborização pelo ataque de pragas e doenças é menor (Silva \& Higuchi, 2008). Com uma diversidade de espécies arbóreas maior, a arborização urbana pode funcionar como um corredor ecológico, contribuindo, assim, para o maior fluxo gênico entre diferentes áreas naturais. Além disso, quando o aumento da diversidade da composição florística vem associado à utilização de espécies nativas, haverá maior conservação da biodiversidade da flora da região por dois motivos: i) conservação genética in vivo das espécies florestais; ii) menor perpetuação das espécies exóticas potencialmente invasoras.

As espécies sugeridas para serem plantadas nas áreas de maior trânsito na cidade foram escolhidas baseando-se na capacidade de suporte de cada espaço e na adaptação da espécie às condições climáticas da região, dando prioridade à utilização de espécies nativas da região. Porém, devido aos atributos paisagísticos de algumas espécies, estas 
também foram sugeridas para o plantio, embora sejam nativas de outros biomas do Brasil, mas adaptadas ao clima da região.

Na Rua Anacleto da Silva Ortiz, as espécies foram sugeridas respeitando-se também o projeto de reurbanização da rua. Neste projeto, os canteiros possuem a largura de $50 \mathrm{~cm}$ e as calçadas são mais largas em determinados pontos, os quais deverão receber a arborização. Como a fiação elétrica se manterá em um dos lados da rua principal, abaixo desta fiação é indicado o plantio de árvores de pequeno porte, como as sugeridas na Tabela 2. Neste caso, as espécies sugeridas são nativas da região, exceto Calliandra selloi (Spreng.) J.F.Macbr. e Senna pendula (Willd.) H.S.Irwin \& Barneby, de acordo com o banco de dados TreeAtlan 1.0 (Oliveira-Filho, 2009).

Tabela 2 - Espécies arbóreas nativas sugeridas para serem plantadas abaixo da fiação elétrica nas ruas da cidade de São José do Cerrito, SC.

\begin{tabular}{lll}
\hline \multicolumn{1}{c}{ Nome Científico } & \multicolumn{1}{c}{ Família } & \multicolumn{1}{c}{ Nome Popular } \\
\hline Acca sellowiana (O.Berg) Burret & Myrtaceae & Goiabeira-serrana \\
Brunfelsia cuneifolia J.A.Schmidt & Solanaceae & Manacá-da-serra \\
Calliandra selloi (Spreng.) J.F.Macbr. & Fabaceae & Angiquinho \\
Calliandra tweediei Benth. & Fabaceae & Esponjinha \\
Senna pendula (Willd.) H.S.Irwin \& Barneby & Fabaceae & Cássia \\
Tibouchina sellowiana (Cham.) Cogn. & Melastomataceae & Quaresmeira-serrana \\
\hline
\end{tabular}

No lado da rua onde não existe fiação elétrica, é indicado o plantio de espécies de pequeno a médio porte, pois as calçadas são de largura média. Nestas condições, além das espécies apresentadas na Tabela 2, são também recomendadas outras espécies, como as descritas na Tabela 3. As espécies sugeridas na Tabela 3 também são nativas da região, exceto Bauhinia forficata Link (Oliveira-Filho, 2009).

Tabela 3 - Espécies arbóreas nativas de médio porte sugeridas para serem plantadas do lado oposto da fiação elétrica nas ruas da cidade de São José do Cerrito, SC.

\begin{tabular}{ccc}
\hline Nome científico & Família & Nome Popular \\
\hline
\end{tabular}




\begin{tabular}{lll}
\hline Allophylus guaraniticus (A.St.-Hil.) Radlk. & Sapindaceae & Chal-chal \\
Bauhinia forficata Link & Fabaceae & Pata-de-vaca \\
Drimys brasiliensis Miers & Winteraceae & Casca d'anta \\
Gochnatia polymorpha (Less.) Cabrera & Asteraceae & Cambará \\
Ilex paraguariensis A.St.-Hil. & Aquifoliaceae & Erva-Mate \\
Ilex theezans Mart. ex Reissek & Aquifoliaceae & Caúna \\
Styrax leprosus Hook. \& Arn. & Styracaceae & Carne-de-vaca \\
\hline
\end{tabular}

As espécies nativas sugeridas são importantes para manter a biodiversidade da região. Geralmente, os moradores das cidades não têm conhecimento da diversidade arbórea da sua região, utilizando na arborização urbana espécies exóticas que, muitas vezes, não irão desempenhar as mesmas funções ecológicas que as espécies nativas, principalmente em relação à manutenção da fauna local.

Espécies como a quaresmeira-serrana, citada na Tabela 2, além dos benefícios mencionados, são indicadas também para a despoluição, pois as partículas de poeira ficam facilmente retidas em suas folhas pilosas (Silva \& Higuchi, 2008).

Para a Rua Herculano Pereira dos Anjos, que possuiu três indivíduos de Ligustrum japonicum plantados abaixo da fiação elétrica, sugere-se a retirada destes e o plantio de espécies de pequeno (Tabela 2) ou médio (Tabela 3) porte, do lado oposto ao da fiação elétrica. Além disso, como não há calçamento na rua, é sugerida a construção de calçadas largas, mantendo-se um canteiro ao redor das árvores para captação de água e aeração do solo.

Devido a sua atual importância, é indicado que a Rua Manoel Batista de Oliveira receba calçamento nos passeios e posterior arborização com espécies nativas de pequeno (Tabela 2) a médio porte (Tabela 3) do lado oposto da fiação elétrica. Para melhor suporte da arborização, é sugerido que as calçadas sejam feitas com maior largura (mínimo de $3 \mathrm{~m}$ ) e com presença de canteiro (mínimo de $50 \mathrm{~cm}$ de largura).

A Rua João Otávio Garcia também necessita de uma melhoria na arborização, com substituição gradativa dos indivíduos de Ligustrum japonicum por indivíduos de espécies nativas, seguindo a mesma regra proposta acima, de plantio de árvores de pequeno (Tabela 2) ou médio porte (Tabela 3) do lado oposto da fiação elétrica. As ruas da cidade possuem, em média, passeios estreitos $(2,2 \mathrm{~m}$ ) e ruas largas (11 $\mathrm{m})$, onde é recomendado, por Silva \& Higuchi (2008), o plantio somente do lado oposto da fiação elétrica.

Os indivíduos de ipê-amarelo, presentes na Rua Edite Batista, não precisam ser substituídos, por serem espécies nativas de grande beleza cênica e não estarem causando interferências sobre os elementos urbanos. Porém, mesmo não estando causando 
interferências, os indivíduos de Ligustrum japonicum podem ser substituídos por espécies nativas de pequeno a médio porte, como os indicados nas Tabelas 2 e 3.

\section{Praças}

Para aumentar a diversidade de espécies nativas nas praças, uma sugestão seria a substituição por espécies frutíferas da região e, ou, de grande beleza cênica. No caso da Praça Clóris Judith da Silva, sugere-se a retiradas dos alfeneiros, porém, a manutenção das araucárias e da pereira, introduzindo, também, árvores como as citadas na Tabela 4. Todas as espécies sugeridas na Tabela 4 são nativas da região (Oliveira-Filho, 2009). A maioria das espécies sugeridas nesta tabela é da família Myrtaceae, que é a principal fornecedora de frutos comestíveis nativos na região. A implantação de árvores frutíferas nativas nas praças promove a conservação da biodiversidade da fauna e flora da região, sendo que os frutos servem de alimento para os freqüentadores das praças e para os animais que venham a ocorrer no local.

Tabela 4 - Espécies arbóreas nativas indicadas para o plantio nas praças da cidade de São José do Cerrito, SC.

\begin{tabular}{lll}
\hline \multicolumn{1}{c}{ Nome Científico } & \multicolumn{1}{c}{ Família } & \multicolumn{1}{c}{ Nome Popular } \\
\hline Acca sellowiana (O.Berg) Burret & Myrtaceae & Goiabeira-serrana \\
Annona rugulosa (Schltdl.) H.Rainer & Annonaceae & Araticum-de-porco \\
Blepharocalyx salicifolius (Kunth) O.Berg & Myrtaceae & Camboim \\
Campomanesia xanthocarpa O.Berg & Myrtaceae & Guabiroba \\
Erythrina falcata Benth. & Fabaceae & Corticeira-da-serra \\
Eugenia pluriflora DC. & Myrtaceae & Jabuticabeira-do-campo \\
Eugenia pyriformis Cambess. & Myrtaceae & Uvaia \\
Handroanthus albus (Cham.) Mattos & Bignoniaceae & Ipê-amarelo \\
Inga lentiscifolia Benth. & Fabaceae & Ingá \\
Jacaranda puberula Cham. & Bignoniaceae & Caroba \\
Myrcia guianensis (Aubl.) DC. & Myrtaceae & Cambuí \\
Myrrhinium atropurpureum Schott & Myrtaceae & Murtilho \\
\hline
\end{tabular}

\section{CONCLUSÕES}

O grande desafio para arborização brasileira é a valorização da biodiversidade local, pois dessa maneira as florestas urbanas poderiam também servir como um instrumento para 
conservação da biodiversidade. Neste trabalho, verificou-se a baixa riqueza de espécies arbóreas nas áreas de maior trânsito na cidade de São José do Cerrito, tendo como predominância o alfeneiro, uma espécie exótica muito utilizada na arborização urbana das cidades do sul do Brasil. Nas áreas de maior trânsito de São José do Cerrito, essas árvores foram plantadas de forma errônea, sem local adequado e sem espaçamento mínimo entre as plantas e sofreram com podas pesadas e mal conduzidas. Além disso, outros problemas foram observados como: interferência na fiação elétrica (alfeneiros e jerivá) devido à altura alcançada pelas árvores; interferência no trânsito de pedestres, devido à altura das primeiras ramificações de 1,50 m (alfeneiros), sistema radicular aflorante, interferindo no calçamento (alfeneiros).

A opção da retirada de grande parte das árvores existentes e o plantio de novas espécies nativas é uma proposta que deve ser considerada, pois, além de fornecer bemestar aos freqüentadores e melhorar a estética da cidade, ajuda na manutenção da biodiversidade florística da Floresta Ombrófila Mista e na atração da fauna local, fornecendo alimento e habitat.

\section{REFERÊNCIAS BIBLIOGRÁFICAS}

ANGIOSPERM PHYLOGENY GROUP II. An update of the angiosperm phylogeny group classification for the orders and families of flowering plants: APG II. Botanical Journal of the Linnean Society, v.143, p. 399-436, 2003.

BRUMMITT, R. K.; POWELL, C. E. Authors of plant names. Kew: Royal Botanic Gardens; 1992.

CERRITO. www.cerrito.sc.gov.br. Acesso em: 01 out 2008.

COLTRO, E. M.; MIRANDA, G. M. Levantamento da arborização urbana pública de Irati PR e sua influência na qualidade de vida de seus habitantes. Revista Eletrônica Lato Sensu, ano 2, n. 1. jul. 2007. Disponível em:

web03.unicentro.br/especializacao/revista/edicao2/engenharias/EN_LevArbo.pdf. Acesso em: 10 out 2008.

FLORIANO, E. P.; GRACIOLI, C. R.; FLORIANO, A. M.; FLORIANO, R. M. M. Censo da arborização da região central da cidade de Horizontina/RS. Santa Rosa/RS: ANORGS, 
Prefeitura Municipal de Horizontina, Conselho do Meio Ambiente, 2004. 69 p. (Trabalho Técnico-Científico, 02).

GREY, G. W.; DENEKE, F. J. Urban forestry. New York: John Wiley, 1978. 279p.

IBGE. Manual técnico da vegetação brasileira. Rio de Janeiro: Fundação Instituto Brasileiro de Geografia e Estatística, 1992. (Série: Manuais técnicos em geociências n. 1).

IBGE - Instituto Brasileiro de Geografia e Estatística. Censo demográfico 2007. Rio de Janeiro: IBGE. www.ibge.gov.br/home. Acesso em: 10 out 2008.

INSTITUTO CEPA/SC. Lages: caracterização regional. http://cepa.epagri.sc.gov.br/Publicacoes/diagnostico/LAGES.pdf. Acesso em: 7 nov 2009.

INSTITUTO HORUS. Espécies invasoras. http://www.institutohorus.org.br/. Acesso em: 7 nov 2009.

MILANO, M. S. Arborização de ruas de Curitiba/PR: uma análise qualitativa. In: Encontro Nacional sobre Arborização Urbana, 1., 1985, Porto Alegre. Anais. Porto Alegre: Secretaria do Meio Ambiente, 1985. p. 83-86.

OLIVEIRA-FILHO, A. T. TreeAtlan versão 1.0. http://www.icb.ufmg.br/treeatlan/. Acesso em: 7 nov 2009.

RODRIGUES, C. A. G.; BEZERRA, B. C. ; ISHII, I. H.; CARDOSO, E. L. Arborização Urbana e Produção de Mudas de Essências Florestais Nativas em Corumbá, MS. Corumbá: Embrapa Pantanal, 2002. 26p.

SILVA, A. C.; HIGUCHI, P. Apostila: Arborização Urbana. Lages: Universidade do Estado de Santa Catarina, 2008. 160p.

SILVA, L. M. Reflexões sobre a identidade arbórea das cidades. Revista da Sociedade Brasileira de Arborização Urbana, v.3, n.3, p. 65-71, 2008. 
SILVA, L. M.; HASSE, I.; MOCCELIN, R. Arborização de vias públicas e a utilização de espécies exóticas: o caso do Bairro Centro de Pato Branco/PR. Scientia Agrária, v.8, n.1, p. 47-53, 2007.

SILVA, L. M.; RODIGHIERO, D. A.; HASSE, I; CADORIN, D. A. Arborização dos bairros Pinheiros, Brasília e Bancários em Pato Braço/PR. Scientia Agrária, v.9, n.3, p. 275-282, 2008. 